\title{
Esophageal Cancer Patients with Less Lymph Node Dissection May Have Better Prognosis
}

\author{
Hannan Wang1*, Yong Jia ${ }^{2 *}$, Chengxue Dang1, Kun Zhu1, Kang Li1 \\ ${ }^{1}$ Department of Surgical Oncology, First Affiliated Hospital of Xi'an Jiaotong University, Xi'an, China \\ ${ }^{2}$ Department of Surgical Thoracic, The Center Hospital of Baoji, Baoji, China \\ Email: hnnwang@gmail.com
}

Received 17 May 2016; accepted 8 July 2016; published 11 July 2016

Copyright (C) 2016 by authors and Scientific Research Publishing Inc.

This work is licensed under the Creative Commons Attribution International License (CC BY).

http://creativecommons.org/licenses/by/4.0/

(c) (i) Open Access

\begin{abstract}
Background: China is a high incidence area of esophageal cancer. Esophageal squamous cell carcinoma recurrence and mortality rates are relatively high. Recent studies show that the recurrence rate remains very high even through the implementation of lymph node expanding dissection. Methods and Results: In order to study the relationship between lymph node dissection number and survival of the patients with esophageal squamous cell carcinoma, 407 cases of esophageal cancer are selected in the First Affiliated Hospital of Xi'an Jiaotong University from January 2009 to June 2013. There were 15 cases without surgery, while the rest of the 392 patients were post-operation in follow-up. 54 patients were lost in follow-up, and the rate was $13.8 \%$. Finally, there were 338 patients entered into our research. The median age was 58 (37 - 81), males accounted for $79 \%$. The number of lymph node dissection is for a total of 2091, and a median of 5 . Positive lymph nodes are 400 , while the total positive rate is $19.1 \%$. Conclusion: The number of lymph node dissection is divided into 3 groups that are 0 to 6,7 to 11,12 or more into three grades, and reduced number of lymph node dissection may prolong the survival $(P<0.05)$. The number of lymph node dissection should be as less as possible unless there is definitely positive lymph node metastasis.
\end{abstract}

\section{Keywords}

Esophageal Resection, Lymphadenectomy, Survival Analysis

\section{Introduction}

In 2013, there were 17,990 new cases of esophageal cancer in the United States. And it was estimated that there

"These authors contributed equally to this work.

How to cite this paper: Wang, H.N., Jia, Y., Dang, C.X., Zhu, K. and Li, K. (2016) Esophageal Cancer Patients with Less Lymph Node Dissection May Have Better Prognosis. Journal of Biosciences and Medicines, 4, 45-52.

http://dx.doi.org/10.4236/jbm.2016.47006 
would be 15,210 death cases of esophageal cancer patients. The five-year survival rate of esophageal cancer is 17.3\% according to the 2003-2009 SEER data. The World Health Organization lists EC as the eighth most common cancer worldwide, and the sixth most common cause of death.

According to the 2015 Chinese national cancer registration records [1] the incidence of esophageal cancer, which ranked as No. 3 in all malignancies in China, is 477.9/100,000 in National Cancer Registry region in the most recent 3 years (2009 to 2011). The incidence in rural is higher 2.22-fold than that in urban. The age-standardized incidence difference increases to 2.09-fold.

In the same period, esophageal cancer mortality was 375.0/100,000, 2.20-fold higher in rural than in urban. The mortality ranked as No. 4 in all malignancies.

Surgery is considered an essential part of the treatment of patients with EC. With more and more research on esophageal cancer, the esophageal surgery technology is also constantly improved. But in the implementation of esophageal surgical, the lymph node cleaning scope has caused considerable controversy.

American and European scholars' study shows that in the early stage esophageal cancer may have potential metastatic [2] and high jumping metastasis [3] rate. Moreover, even with lymph node metastasis, lymph node dissection positive rate is relatively low. Western scholars treat esophageal cancer as a systemic disease that cannot just pursue lymph nodes dissection completely. It's necessary to find a balance between the minimal quantity of the lymph node dissection and the best survival to reduce the surgical trauma and to maintain the integrity of the organ function to improve the postoperative survival quality, reduce complications and mortality.

Japanese scholars believe that since early esophageal cancer has metastasis so lymph nodes should be dissected as many as possible early, and the median number is usually 70. They think that esophageal cancer is a disease of regional neck, mediastinum and upper abdomen, so they continue to expand the scope of lymph node dissection, from the traditional one-field lymphadenectomy (lower mediastinal and upper abdomen) to the two field lymph node dissection (2FD), and finally to the current three-field lymph node dissection (neck). Now the lymph node mino (3FD) has become the standard operation for the vast majority of Japanese hospital.

In China, most of "selective three-field lymph node dissection" is used among the patients with suspected neck lymph node metastasis. But the patients without the cervical lymph node metastasis would not receive 3FD. While the 5-year survival of 3FD surgery in Japan has been significantly increased from 30\% to 50\%, early postoperative complication rate and mortality is relatively high. At the same time, the 3FD surgical trauma is too large for carcinoma in situ (DCIS), and the risks are very high for elderly patients and those with poor general condition. So the 2FD is the main operation for esophageal cancer in China.

Even 2FD, the number of lymph node dissection is also different: Shen, Y. et al. [4]-[7] found that it was meaningful when the number of lymph node excision between 13 - 38. Shawn S. [8] et al. Research shows that the cases of lymph node dissection more than 12 can significantly increase fatality rate, while more than 30 lymph nodes in patients with the lowest mortality. Rizk [9] et al. research showed that when the number of positive lymph nodes more than 7, it did not make any sense to expand the lymph nodes to improve patient survival [10].

The purpose of this paper is to study if the different number of lymph node dissection effects on the prognosis of EC.

\section{Patients and Methods}

\subsection{General Data}

407 cases of esophageal cancer were selected in the First Affiliated Hospital of Xi'an Jiaotong University from January 2009 to June 2013. The exclusion criteria are listed as below: without operation treatment; secondary primary cancer; neoadjuvant chemotherapy; unable to be followed up; serious cardiovascular disease.

All patients with TNM staging is clear, Stage I 10 cases, II A 144 cases, 164 cases of stage II B + III, Stage IV 20 cases. There are 14 cases of T1, 66 cases of T2, 213 cases of T3, 45 cases of T4; N0 in 181 patients, 104 cases of N1, 39 cases of N2, 14 cases of N3; There are 318 cases of M0 and 20 cases of M1.

Clinical staging using EUS (with FNA if indicated), chest and abdomen CT scan, and PET scan (integrated PET/CT preferred over PET alone) should be performed before surgery to assess resectability. We put the patients into three groups by the difference of lymph nodes dissection: the first group of numbers 0 - 6 sweeping, the second group of 7 to 11 the number of cleaning, sweeping the third group number 12 or above, in order to study the relationship between the number of lymph node dissection and prognosis. 


\subsection{Follow-Up}

The patients were followed up every 3 months after the operation in the $1^{\text {st }}$ year and then every 6 months. There were 15 cases without surgery. The rest of the 392 patients were followed up until October 2013. 54 patients were lost to follow-up and the lost follow-up rate was $13.8 \%$. Finally, there are 338 patients entered into our research.

\subsection{Statistical Analysis}

We calculate the survival rate and survival period and univariate analysis by Kaplan Meier method, compare differences between groups by Log-rank test, and by Cox proportional hazards model for multiple factors analysis. P $<0.05$ is considered statistically significant. The software is SPSS20.0 provided by IBM (Chicago America).

\section{Results}

Univariate analysis is conducted in addition to the factors such as tumor staging, chemotherapy, lymph node classification. We find that when the number of lymph node dissection is 0 to 6,7 to 11 and more than 12 of these three groups influence on survival (Table 1$)$ and the difference is statistically significant $(P<0.05)$.

Although we get the graph of the number of node dissection impact on survival, when the number of lymph

Table 1. Results of survival analysis performed by SPSS.

\begin{tabular}{|c|c|c|c|c|}
\hline Factor & patient & chi-square & $95 \%$ CI & $P$ value \\
\hline ALL & 338 & & & \\
\hline Gender & & 0.279 & & 0.598 \\
\hline Male & 267 & & $38.08-42.96$ & \\
\hline Female & 71 & & $36.45-45.84$ & - \\
\hline Residence & & 1.284 & & 0.257 \\
\hline Urban & 137 & & $38.84-45.53$ & \\
\hline Country & 201 & & $36.75-42.47$ & \\
\hline Age (years) & & 4.20 & & 0.24 \\
\hline $36-45$ & 24 & & $39.78-53.93$ & \\
\hline $46-55$ & 101 & & $35.83-43.84$ & \\
\hline $56-65$ & 165 & & $38.19-44.09$ & \\
\hline $66 \sim$ & 48 & & $30.36-41.39$ & \\
\hline Regional Lymph Nodes & & 23.04 & & $<0.05$ \\
\hline N0 & 181 & & $42.89-48.38$ & \\
\hline $\mathrm{N} 1$ & 104 & & $32.42-40.41$ & \\
\hline N2 & 39 & & $27.42-38.96$ & \\
\hline N3 & 14 & & $20.94-38.17$ & \\
\hline Anatomic Stage & & 23.79 & & $<0.05$ \\
\hline I & 10 & & $29.33-40.67$ & \\
\hline II A & 144 & & $43.59-49.62$ & \\
\hline IIB-III & 164 & & $34.14-40.43$ & \\
\hline IV & 20 & & $21.79-37.25$ & \\
\hline Numberof lymph node dissection & & 6.07 & & 0.048 \\
\hline $0-6$ & 211 & & $39.77-45.19$ & \\
\hline $7-11$ & 78 & & $35.83-44.40$ & \\
\hline $12 \sim$ & 49 & & $28.54-39.35$ & \\
\hline Distant Metastasis & & 8.70 & & 0.003 \\
\hline M0 & 318 & & $39.32-43.77$ & \\
\hline M1 & 20 & & $21.79-37.25$ & \\
\hline
\end{tabular}


nodes dissection in 0 - 6 the patients survival rate is better than that in $7-11$. It is the worst when the number is more than 12. But some of confounding and bias makes results less credible. To study how the number of lymph node dissection affected on survival, we explained in detail in the following aspects.

\subsection{Different Chemotherapy Regimens}

Patients with esophageal cancer when he was found in advanced, need adjuvant chemotherapy after surgery to achieve better survival. In this study, 280 patients (83\%) patients received postoperative chemotherapy. Among them the number with FLP scheme chemotherapy was 102, 91 NP scheme, 52 TP scheme, 6 MDT, other chemotherapy regimens of 29. A total of 58 cases of chemotherapy regimens is unknown.

When grouping them according to the different chemotherapy regimens and survival analysis we found that the difference was statistically significant $(\mathrm{P}<0.05)$. When we selected chemotherapy to study the relationship between the number of lymph node dissection and survival, the difference is not considerably significant (Figure 1(a)). But we can see that the NP program and FLP program have the same trend of survival curves: the group of lymph node dissection in 0 - 6 has the highest survival rate, 7 to 11 of the second, better than 12 or above (Figure 1(b), Figure 1(c)). But in the survival curve of TP scheme: The number of lymph node dissection in the highest survival rate of 7 to 11, followed by 0 to 6 , better than 12 or above (Figure 1(d)).

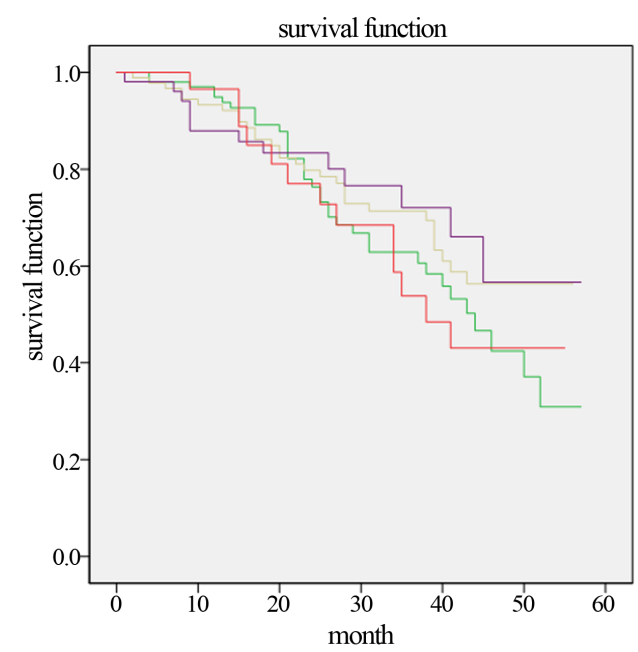

(a)

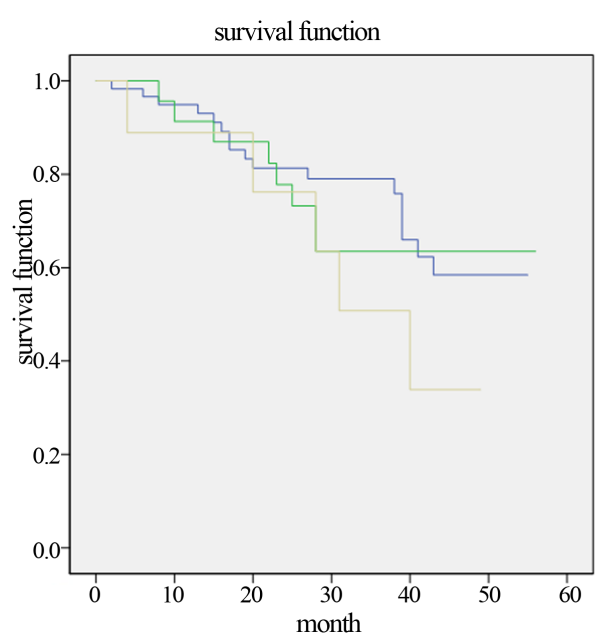

(c)

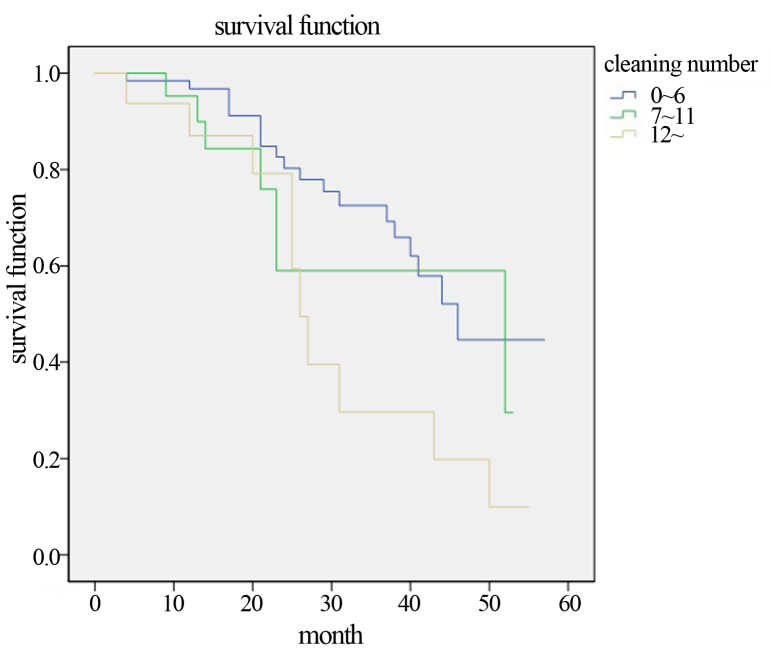

(b)

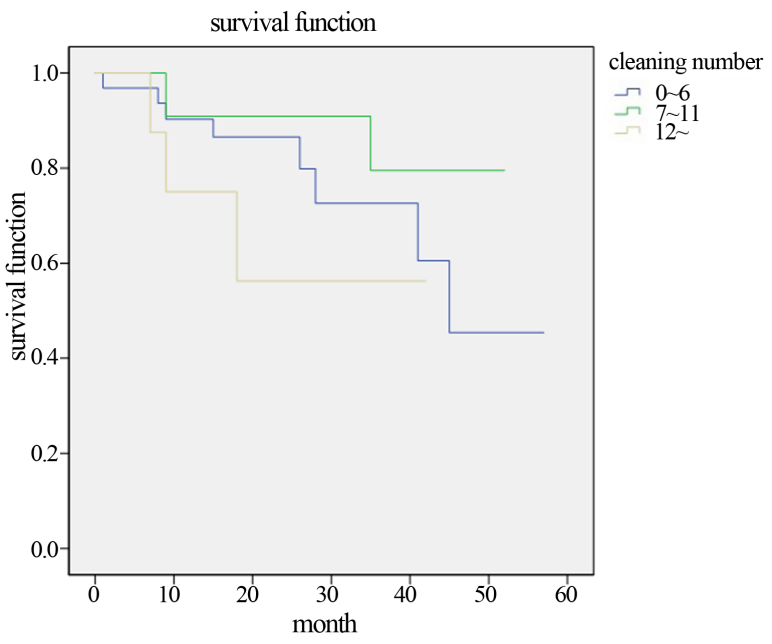

(d)

Figure 1. The survival curve of different chemotherapy regimens. (a) The difference of the survival rate of different chemotherapy regimens; (b) FLP scheme; (c) NP scheme; (d) TP scheme. 


\subsection{Different Lymph Node Classification}

As most of the previous studies, our study also proved that with the increase of lymph node classification, survival rates continue to decline $(\mathrm{P}<0.001)$, and the difference was considerably significant $(\mathrm{P}<0.05)$. Lymph node classification can be described as a clinical prognostic indicator (Figure 2(a)).

But when we choose a level of lymph node dissection to study the relationship between the number of lymph node dissection and survival rates, it can be obtained the following results: although difference in survival curves of N1 and N2 was not obvious (Figure 2(c), Figure 2(d)), but in the survival curves of N0, we can see the survival of the number of lymph nodes from 0 to 6 is the best, followed by 7 to 11, more than 12 Worst (Figure 2(b)).

\subsection{Different Pathological Classification of Esophageal Cancer}

For the convenience of our study to patients in accordance with tumor staging that is divided into four levels (stage I, stage II A, stage II B-III and stage IV). The significance of this division is: stage I patients with primary tumors and no lymph node metastasis, stage II A patients with second grade primary tumors and no lymph node metastasis, stage II B-III patients with third grade primary tumors and regional lymph node metastasis, stage IV

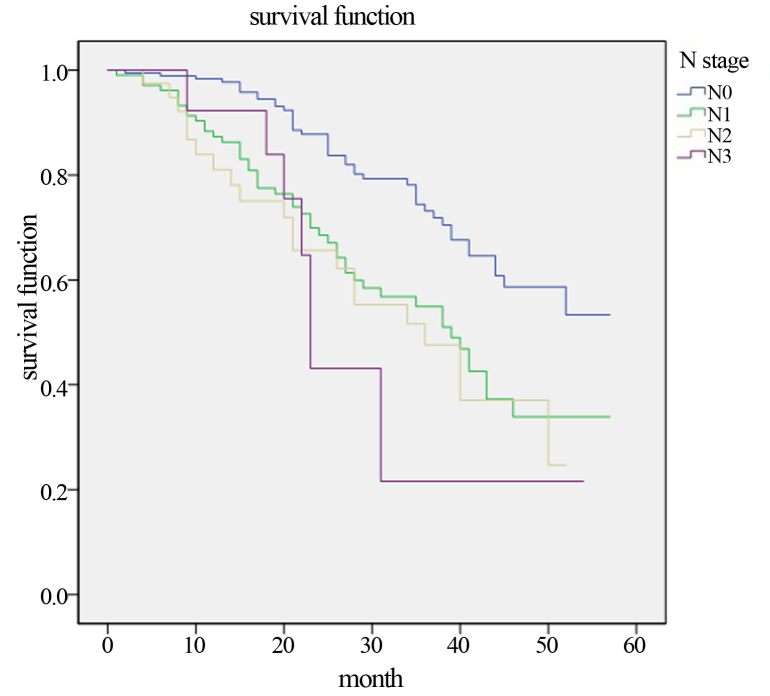

(a)

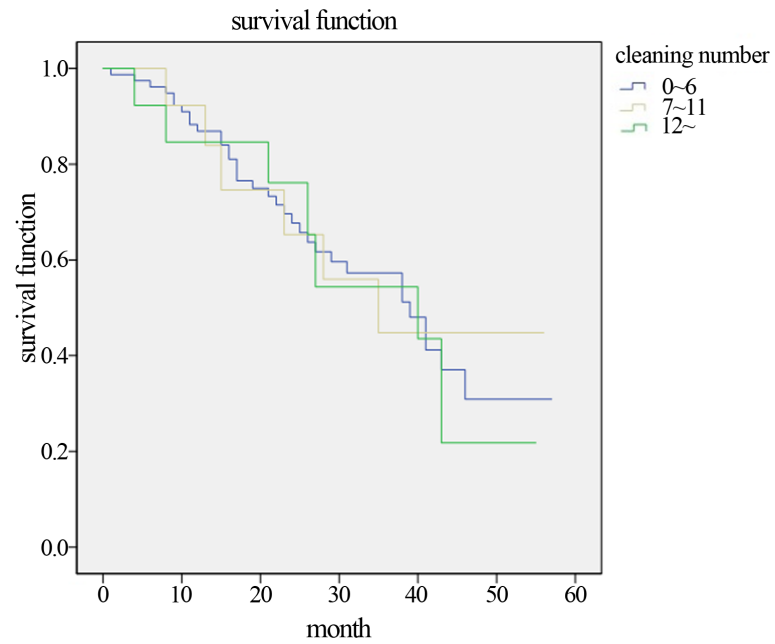

(c)

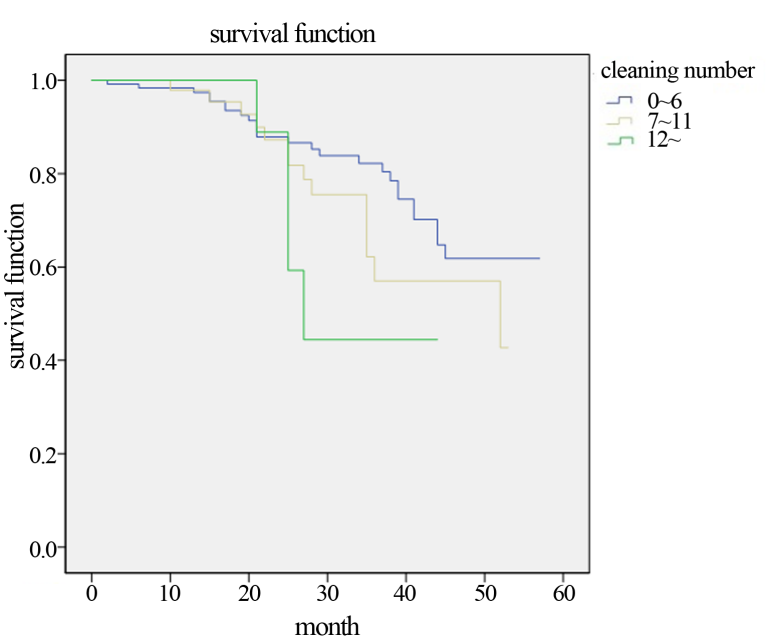

(b)

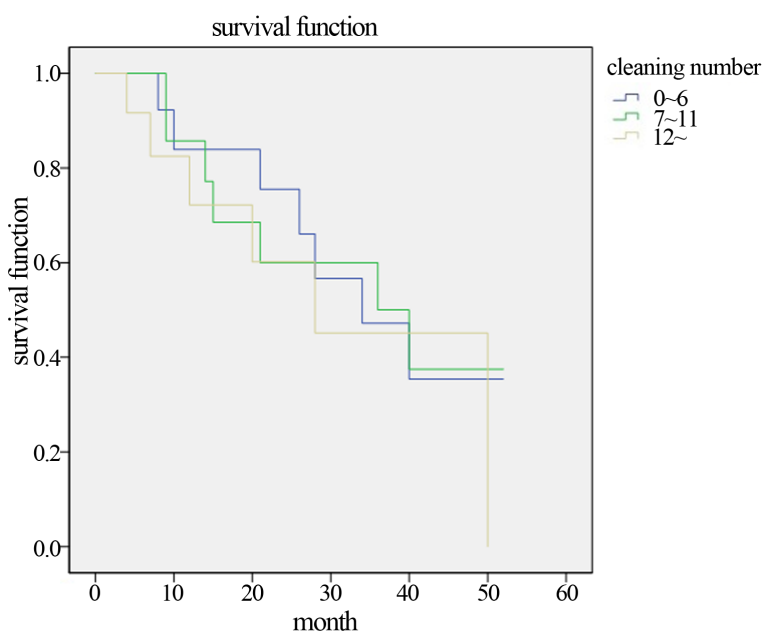

(d)

Figure 2. The survival curve of different lymph nodes classification. (a) The difference of the survival rate among N0, N1 and N2 classification; (b) N0 classification; (c) N1 classification; (d) N2 classification. 
patients have distant organ metastasis. The number of stage I patients in this study is too little to research.

Our study also demonstrated that as the increase of pathological stage of esophageal cancer, the survival rate continues to decline $(\mathrm{P}<0.05)$ (Figure 3(a)).

When we choose a pathological stage of esophageal cancer to study the relationship between the number of lymph node dissection and survival rates, it can be obtained the following results $(\mathrm{P}>0.05)$ : the survival curves of II A patients display the number of lymph nodes from 0 to 6 survival preferably, 7 to 11 as the second, better than 12 or above (Figure 3(b)). The survival curves of stage II B-III patients show that there is no difference between the number of lymph nodes from 0 to 6 and 7 to 11, but better than the survival rate of 12 or more (Figure 3(c)); the survival curves of stage IV patients display when the number of lymph nodes dissection is more than 12 the patients had the highest survival rate (Figure 3(d)).

\section{Discussion}

The results of the study show that it's not proper to choose lymph node enlargement cleaning directly. Clinical physicians should seek reasonable and effective treatment options based on the specific circumstances of each patient to improve their survival and choose a different number of lymph node dissection according to esophageal cancer in different positions and pathological stage.

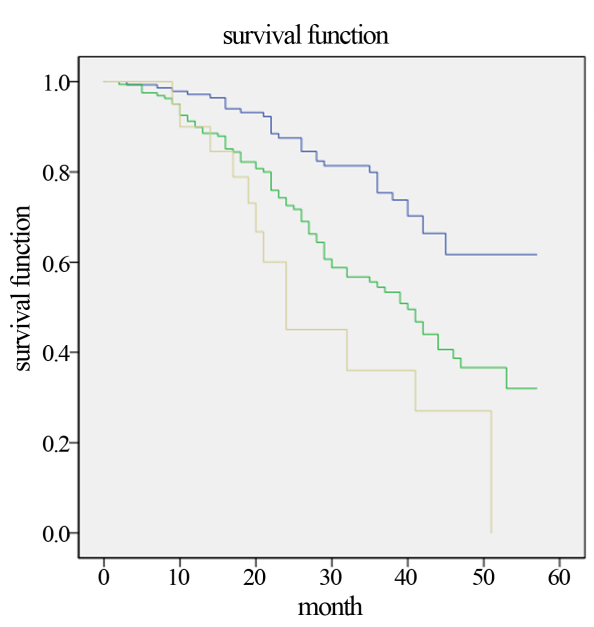

(a)

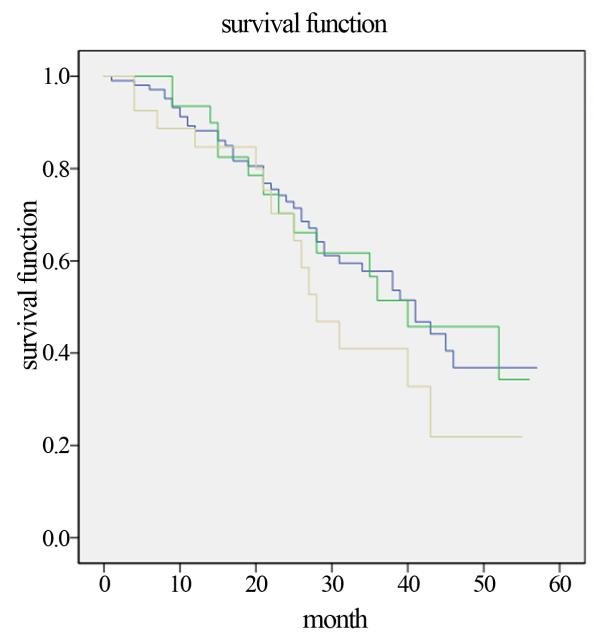

(c)

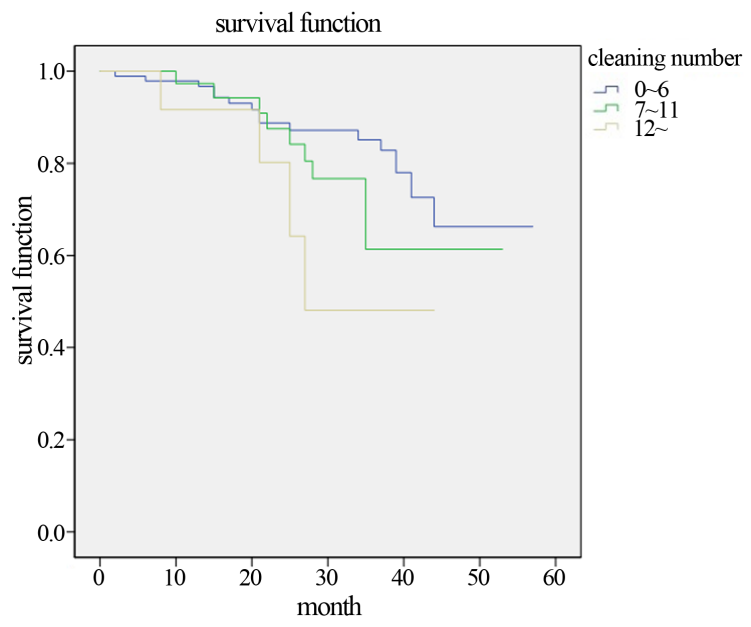

(b)

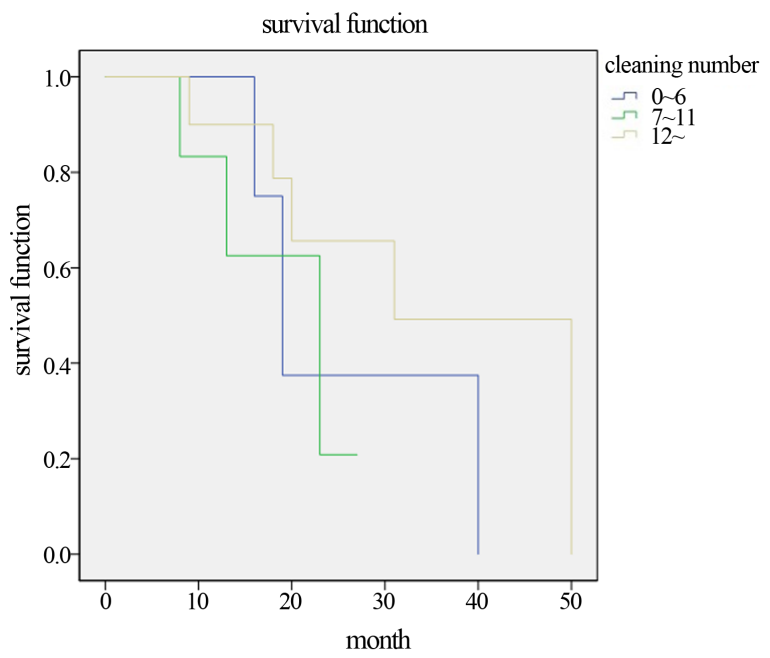

(d)

Figure 3. The survival curve of different pathological stage. (a) The difference of the survival rate of different pathological stage; (b) Stage II A; (c) Stage II B-III; (d) Stage IV. 
For patients with esophageal cancer considered no local lymph node metastasis the lymph node should be dissected as less as possible, because we can see the number of lymph nodes from 0 to 6 have the best survival rates in the survival curves of N0.

For patients who need postoperative chemical therapy, the lymph node should be dissected less. The survival curve of FLP, TP and NP programs have the same trend: the survival rate of lymph nodes dissected more than 12 is the worst.

Furthermore, the following two reasons may also affect patient survival.

Recent study shows that postoperative esophageal cancer recurrence rate is relatively high. And just surgery is not the best method recommended. Sjoquist, K.M. [11] et al.'s study showed that the result of surgery alone was often not satisfactory. Prenzel K.L. et al.'s study showed that postoperative adjuvant chemotherapy could improve the survival of three years and reduce the positive lymph nodes. Our study demonstrated that different chemotherapy regimens may affect the prognosis [12].

Perioperative care has a certain impact on survival because patients with esophageal cancer during the diagnosis-treatment-recovery entire process are under tremendous physical and psychological pressure. The dietary habit change after surgery requires proper nutritional intake. We observed that the higher living standard and the sound health care is an important reason of a better survival in urban patients based on our research that shows the survival rate of patients in rural areas is lower than that in the city.

So we have to take the appropriate chemotherapy regimen for different patients at the same time continuously to improve operations level. Furthermore it is essential to enhance the care of patients after surgery to improve the patient's survival.

Chinese health care system and basic medical facilities are still not sound so that the majority of patients cannot get early diagnosis and treatment. Many people won’t go to hospital until dysphagia, at this time $74.5 \%$ 73.0\% [13] of the patients with lymph node metastasis by autopsy. Vashist Y.K. [14]-[16] study shows that 20 to 30 percent of esophageal cancer patients at the time of first diagnosis have occurred bone metastasis. If at this time expanding lymph node dissection is conducted, not only cleaning up a lot of normal lymph nodes in patients with reduced immune function, but also increasing the trachea and the recurrent laryngeal nerve injury, and increasing the incidence of mortality and complications.

3FD should be limited to the patients with relatively early lesions or patients considered in the clinical stage IV stage and cancer lesion limited. It's recommended to decrease the possibility of radical surgery, once the extensive lymph node metastasis is found [18]. The primary purpose should be to improve the quality of life of the patients.

Igaki $\mathrm{H}$ et al. found that survival rates of patients with two-field and three-field lymphadenectomy had no difference [17]-[19]. Hiroshi M. [20] et al. think that the location of resection lymph nodes rather than the total number of resection may be more important to improve the survival. Thus the present study suggests that however the operation approach is conducted the number of lymph node dissection should be as less as possible unless there is definitely positive lymph node metastasis.

This study still remains such limitations as: samples that confined to just one hospital with less representative, insufficient follow-up time, the lack of pathological tumor size, incomplete specific surgical information. And as a case review study selection bias cannot be avoided completely. It's necessary to follow up more post-operation patients from different clinical centers for a further study.

\section{References}

[1] Chen, W.Q., Zheng, R.S., Baade, P.D., Zhang, S.W., Zeng, H.M., He, J., et al. (2016) Cancer Statistics in China, 2015. CA: A Cancer Journal for Clinicians.

[2] Gockel, I., Sgourakis, G., Lyros, O., Polotzek, U., Schimanski, C.C., Lang, H., et al. (2011) Risk of Lymph Node Metastasis in Submucosal Esophageal Cancer: A Review of Surgically Resected Patients. Expert Review of Gastroenterology \& Hepatology, 5, 371-384. http://dx.doi.org/10.1586/egh.11.33

[3] Bollschweiler, E., Baldus, S.E., Schröder, W., Prenzel, K., Gutschow, C., Schneider, P.M., et al. (2006) High Rate of Lymph-Node Metastasis in Submucosal Esophageal Squamous-Cell Carcinomas and Adenocarcinomas. Endoscopy, 38, 149-156. http://dx.doi.org/10.1055/s-2006-924993

[4] Baba, M., Aikou, T., Yoshinaka, H., Natsugoe, S., Fukumoto, T., Shimazu, H., et al. (1994) Long-Term Results of Subtotal Esophagectomy with Three-Field Lymphadenectomy for Carcinoma of the Thoracic Esophagus. Annals of Surgery, 219, 310. http://dx.doi.org/10.1097/00000658-199403000-00012 
[5] Sharma, S., Fujita, H., Yamana, H. and Kakegawa, T. (1994) Patterns of Lymph Node Metastasis in 3-Field Dissection for Carcinoma in the Thoracic Esophagus. Surgery Today, 24, 410-414. http://dx.doi.org/10.1007/BF01427033

[6] Ando, N., Ozawa, S., Kitagawa, Y., Shinozawa, Y. and Kitajima, M. (2000) Improvement in the Results of Surgical Treatment of Advanced Squamous Esophageal Carcinoma during 15 Consecutive Years. Annals of Surgery, $232,225$. http://dx.doi.org/10.1097/00000658-200008000-00013

[7] Shen, Y., Zhang, Y., Tan, L., Feng, M., Wang, H., Khan, M.A., Liang, M., et al. (2012) Extensive Mediastinal Lymphadenectomy during Minimally Invasive Esophagectomy: Optimal Results from a Single Center. Journal of Gastrointestinal Surgery, 16, 715-721. http://dx.doi.org/10.1007/s11605-012-1824-7

[8] Groth, S.S., Virnig, B.A., Whitson, B.A., De For, T.E., Li, Z.Z., Tuttle, T.M., et al. (2010) Determination of the Minimum Number of Lymph Nodes to Examine to Maximize Survival in Patients with Esophageal Carcinoma: Data from the Surveillance Epidemiology and End Results Database. The Journal of Thoracic and Cardiovascular Surgery, 139, 612-620. http://dx.doi.org/10.1016/j.jtcvs.2009.07.017

[9] Rizk, N.P., Ishwaran, H., Rice, T.W., Chen, L.Q., Schipper, P.H., Kesler, K.A., et al. (2010) Optimum Lymphadenectomy for Esophageal Cancer. Annals of Surgery, 251, 46-50. http://dx.doi.org/10.1097/SLA.0b013e3181b2f6ee

[10] Bottger, T., Terzic, A. and Muller, M. (2006) Extent of Lymphnode Dissection with Minimally Invasive Esophageal Resection. Zentralblatt fur Chirurgie, 131, 466-473.

[11] Sjoquist, K.M., Burmeister, B.H. and Smithers, B.M. (2011) Survival after Neoadjuvant Chemotherapy or Chemoradiotherapy for Resectableoesophageal Carcinoma: An Updated Meta-Analysis. The Lancet Oncology, 12, 681-692. http://dx.doi.org/10.1016/S1470-2045(11)70142-5

[12] Oezcelik, A., Kaiser, G.M., Niebel, W., Sleyman, C., Treckmann, J.W., Sotiropoulos, G.C., et al. (2012) Ten-Year Survival of Esophageal Cancer after an En-Bloc Esophagectomy. Journal of Surgical Oncology, 105, 284-287. http://dx.doi.org/10.1002/jso.22096

[13] Mandard, A.M., Chasle, J., Marnay, J., Villedieu, B., Bianco, C., Roussel, A., et al. (1981) Autopsy Findings in 111 Cases of Esophageal Cancer. Cancer, 48, 329-335. http://dx.doi.org/10.1002/1097-0142(19810715)48:2<329::AID-CNCR2820480219>3.0.CO;2-V

[14] Natsugoe, S., Nakashima, S., Nakajo, A., Matsumoto, M., Okumura, H., Tokuda, K., et al. (2003) Bone Marrow Micrometastasis Detected by RT-PCR in Esophageal Squamous Cell Carcinoma. Oncology Reports, 10, 1879-1883.

[15] Nakamura, T., Matsunami, K., Hayashi, K., Ota, M., Ide, H. and Takasaki, K. (2004) Detection of Bone Marrow Micrometastasis in Esophageal Cancer Patients by Immunomagnetic Separation. Oncology Reports, 11, 999-1003.

[16] Vashist, Y.K., Effenberger, K.E., Vettorazzi, E., Riethdorf, S., Yekebas, E.F., Izbicki, J.R., et al. (2012) Disseminated Tumor Cells in Bone Marrow and the Natural Course of Resected Esophageal Cancer. Annals of Surgery, 255, 11051112. http://dx.doi.org/10.1097/SLA.0b013e3182565b0b

[17] Nishihira, M.D., Hirayama, M.D. and Mori, M.D. (1998) A prospective Randomized Trial of Extended Cervical and Superior Mediastinal Lymphadenectomy for Carcinoma of the Thoracic Esophagus. The American Journal of Surgery, 175, 47-51. http://dx.doi.org/10.1016/S0002-9610(97)00227-4

[18] Tabira, Y., Okuma, T., Kondo, K. and Kitamura, N. (1999) Indications for Three-Field Dissection Followed by Esophagectomy for Advanced Carcinoma of the Thoracic Esophagus. The Journal of Thoracic and Cardiovascular Surgery, 117, 239-245. http://dx.doi.org/10.1016/S0022-5223(99)70418-6

[19] Igaki, H., Tachimori, Y. and Kato, H. (2004) Improved Survival for Patients with Upper and/or Middle Mediastinal Lymph Node Metastasis of Squamous Cell Carcinoma of the Lower Thoracic Esophagus Treated with 3-Field Dissection. Annals of Surgery, 239, 483. http://dx.doi.org/10.1097/01.sla.0000118562.97742.29

[20] Miyata, H., Yamasaki, M., Makino, T., Miyazaki, Y., Takahashi, T., Kurokawa, Y., et al. (2015) Therapeutic Value of Lymph Node Dissection for Esophageal Squamous Cell Carcinoma after Neoadjuvant Chemotherapy. Journal of Surgical Oncology, 112, 60-65. http://dx.doi.org/10.1002/jso.23965 


\section{Submit or recommend next manuscript to SCIRP and we will provide best service for you:}

Accepting pre-submission inquiries through Email, Facebook, Linkedin, Twitter, etc A wide selection of journals (inclusive of 9 subjects, more than 200 journals)

Providing a 24-hour high-quality service

User-friendly online submission system

Fair and swift peer-review system

Efficient typesetting and proofreading procedure

Display of the result of downloads and visits, as well as the number of cited articles

Maximum dissemination of your research work

Submit your manuscript at: http://papersubmission.scirp.org/ 